\title{
Stress Responses during Milking; Comparing Conventional and Automatic Milking in Primiparous Dairy Cows
}

\author{
H. Hopster, ${ }^{\star}$ R. M. Bruckmaier,† J. T. N. Van der Werf, ${ }^{\star}$ S. M. Korte, ${ }^{\star}$ \\ J. Macuhova, $\dagger$ G. Korte-Bouws, ${ }^{*}$ and C. G. van Reenen* \\ *Institute for Animal Science and Health, Divison of Animal Sciences, \\ P.O. Box 65, 8200 AB, Lelystad, The Netherlands \\ †Institute of Physiology, Technical University of Munich, \\ Weihenstephaner Berg 3, D-85350, \\ Freising, Germany
}

\section{ABSTRACT}

A comparative study was performed to evaluate the differences in behavioral and physiological stress responses during milking between cows that were milked by an automated milking system (AM-cows) and cows that were milked in a conventional tandem parlor (TMcows). In a randomized design, 36 primiparous Holstein-Friesian dairy cows were observed and blood sampled (1-min intervals) individually during milking. AMcows spent less time standing with their heads outside the feeding trough than TM-cows and had a lower heart rate. In addition, AM-cows had lower maximum plasma adrenaline and noradrenaline concentrations during milking. No differences were found in the number of steps. After tactile stimulation of the teats either by hand or by the cleaning brush, mean oxytocin concentrations did not differ. In AM-cows, however, elevated oxytocin levels were prolonged at the end of milking. Averaged over the first five blood samples, AM-cows tended to have higher plasma cortisol concentrations than TM-cows, but median fecal concentrations of the cortisol metabolite dioxoandrostane were comparable. Maximum quarter milk flow, maximum udder milk flow and residual milk as a percentage of the total milk volume was comparable. From this study it is concluded that behavioral and physiological responses, both in automatically and in conventionally milked cows, were relatively low and were typical for cows being milked. We therefore conclude that, as far as the welfare of the dairy cow during milking is concerned, automatic milking and conventional milking are equally acceptable.

(Key words: stress, automatic milking, behavior, hormone)

Received April 3, 2001.

Accepted May 9, 2002.

Corresponding author: H. Hopster; e-mail: h.hopster@id. wag-ur.nl.
Abbreviation key: $\mathbf{A}=$ adrenaline, $\mathbf{A M}=$ automatically milked, AMS = automatic milking system, $\mathbf{C S}=$ cortisol, DHBA = dihydroxybenzylamine, $\mathbf{D O A}=11,17$ dioxoandrostanes, $\mathbf{H R}=$ heart rate, $\mathbf{N A}=$ noradrenaline, $\mathbf{O T}=$ oxytocin, $\mathbf{T M}=$ milked in a tandem parlor .

\section{INTRODUCTION}

With respect to the welfare of the dairy cow, the use of automatic milking systems (AMS) has both advantages and disadvantages. One advantage is the increased milking frequency, as more frequent milking has been shown to reduce both bulk milk SCC and the number of cows displaying a new increase in SCC $(>250,000$ cell $/ \mathrm{ml}$ ). This suggests that frequent milking improves udder health (Hogeveen et al., 2000). An AMS, on the other hand, also has the chance of failed cluster attachment, resulting in milk leakage (Stefanowska et al., 2000 ) and thus increasing the risks of mastitis. Furthermore, there is some controversy over the cow's selfdetermination with the AMS. It is argued that by allowing cows to visit the milking unit of their own accord at times that suit them best, the AMS provides the cows with increased control over their environment (Prescott et al., 1998). It has, however, also been demonstrated that for forced cow traffic, low-ranking animals were forced by social competition to visit the AMS at midnight hours (Ketelaar-de Lauwere et al., 1996), suggesting that the AMS does not necessarily give the cow control over her environment. Since animal welfare is a significant issue that has an impact on the public's acceptance of new technology, the AMS must demonstrate excellent technical performance without causing stress responses above the levels that are generally accepted during conventional milking. Speculation about negative effects of automatic milking on the welfare of the dairy cow may easily raise consumer concerns, threaten the welfare-friendly image of dairy farming, and hence reduce the public acceptance of dairy products from automatically milked cows. 
Two aspects that are exclusive to the AMS are the total "automatization" of feeding, teat cleaning, teat cup attachment, milking and teat cup removal, and the way in which the animals visit and leave the milking system on their own accord. The aim of this study is to determine physiological and behavioral stress responses during milking of dairy cows when voluntarily visiting the AMS. To evaluate the animal friendliness of the AMS, we measured the stress response during milking in an AMS compared with the stress response shown in a conventional milking system-a conventional double-three open-tandem milking parlorwhich is widely accepted as meeting current animal welfare standards.

\section{MATERIALS AND METHODS}

The experiment was carried out at the experimental farm of ID-Lelystad between November 1999 and March 2000. All experimental methods for this study were approved by the Institutional Animal Care and Use Committee and certified by ISO 9001.

\section{Animals, Housing, and Management}

Twenty pairs of pregnant heifers were selected and balanced for estimated breeding value (NRS, 1996) and calving date. Primiparous cows were used for this system comparison because these animals have no experience with either milking system and generally show stronger stress responses than multiparous cows. Before calving, all heifers were kept in the same group. For 2 wks before the expected calving date the animals received additional concentrates to adapt them to a dairy ration. One day before the expected calving date, animals were transferred to individual calving pens. One day after calving, they entered a group of freshly calved cows that was milked twice daily in a 32-stall rotary parlor. Twice a week, animals that had calved at least $2 \mathrm{~d}$ earlier were randomly introduced into either the automatic milking (AM) group or a group that was milked in the tandem parlor (TM). Both groups consisted of 50 to 60 cows and were housed in separate cubicle barns. AM-cows had to pass through the milking robot to get from the resting area at the feed gate (forced cow traffic). One-way gates between the feeding and resting area were used to prevent cows from feeding while not having visited the milking system. TM-cows were conventionally milked twice daily in a fully automated double-three open-tandem parlor at $0600 \mathrm{~h}$ and $1600 \mathrm{~h}$. TM-cows had unrestricted access to food. Access to water was unrestricted for both groups. All cows were under the same feeding and management regimen and received a TMR consisting of maize silage (33\%), chopped grass silage (27\%), soybeans and rapeseed (7\%, extracted) and concentrates (AM: 7\%; TM: 19\%). Percentages are on DM basis. The TMR was fed ad libitum at $0630 \mathrm{~h}$ each day. Additional concentrates were delivered during milking according to milk yield (AM: 26\%; TM: $14 \%$ ). At least one cubicle and one feeding place was available for each cow in both groups. An outline of the automatic milking barn is given in Figure 1.

Cows were assigned to three batches according to calving date in such a way that all cows had been able to adapt to the milking system for at least $4 \mathrm{wks}$ before testing. Because of problems after calving in some animals, they could not be used in the experiment and were replaced by others. The restricted number of spare animals, however, did not allow for the replacement of complete pairs, and thus the random allocation of animals to treatment groups could only be partly realized. Finally six AM- and six TM-cows were tested in each batch within one week, totaling 36 animals. Each cow was tested once. AM-cows were tested during milking, which took place between $0800 \mathrm{~h}$ and $1530 \mathrm{~h}$. TMcows were tested during evening milking, between 1600 and $1730 \mathrm{~h}$.

\section{Milking Systems}

The AMS was a commercial single-box system (Lely Astronaut Model 20; Lely Industries NV, Maasland, The Netherlands), which was in use since January 1999. The system was located at the end of the right part of a 4-row cubicle barn (Figure 1). Teat cups were automatically attached one by one. At the end of milking, quarters were detached based on their own milkflow rate, according to the manufacturers' specifications. The system was provided with an electrical movement inductor to remind cows to leave the AMS after they had finished milking. The double-three open-tandem milking parlor was provided with De Laval milking equipment (Liner type 96001689) and electronic milk meters. When the milk flow dropped below $0.2 \mathrm{~kg} / \mathrm{min}$ the cluster automatically detached. Technical specifications of both systems are given in Table 1 .

\section{Habituation, Handling, and Preparation}

All animals were habituated to the test conditions three times on different days according to a predefined protocol in the week before they were tested. Habituation consisted of being approached and caught in the home environment (barn), standing in a cubicle for 30 min while loosely tethered with a rope, wearing a heart rate belt, and being touched by one of the experimenters. In addition, TM-cows were accustomed to being milked at the left side of the milking parlor. All cows 


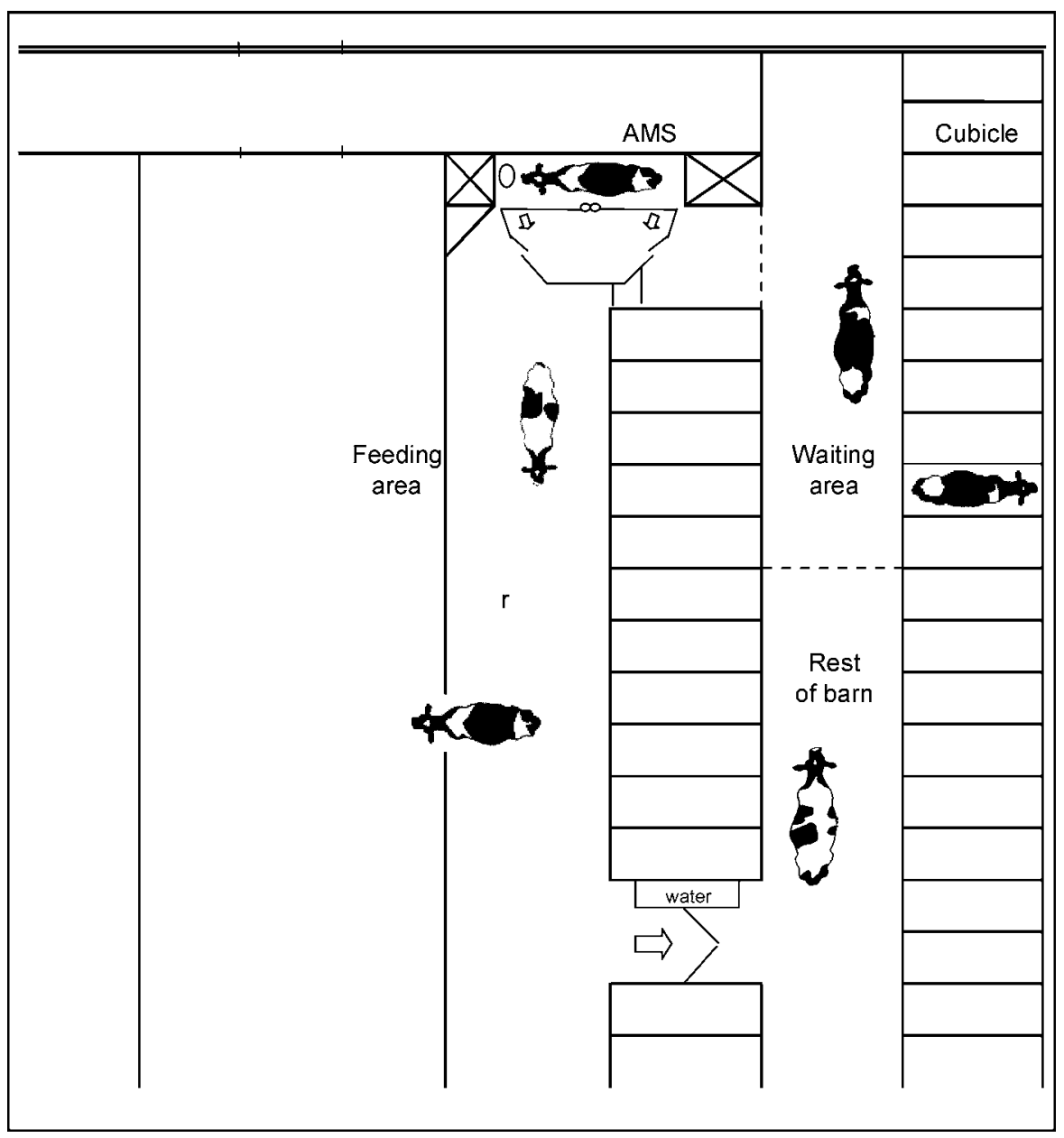

Figure 1. Layout of the automatic milking barn.

were habituated to the experimenter standing next to the cows' heads during milking, to having their necks touched to mimic fetching a jugular cannula, and to the presence of the equipment used for recording quarter milk flow curves. From the first habituation day until the end of the test, cows were provided with a halter to facilitate handling.

Only one set of equipment was available for recording quarter milk flow and, therefore, this had to be transferred from the AMS to the tandem parlor before and replaced after milking in the evening. Therefore, all AM-cows were to be tested between $0800 \mathrm{~h}$ and 1530 $\mathrm{h}$ during a voluntary visit to the AMS. When cows did not show any intention of visiting the AMS before 1400 $\mathrm{h}$, they were gently encouraged to enter the walking area that was near the AMS. Here they were separated from the rest of the herd by a single steel bar. This situation stimulated them to visit the AMS without any further intervention. Cows that were already near the AMS and intended to enter when the first experimenter

Table 1. Technical characteristics of automatic (AM) and conventional (TM) milking systems.

\begin{tabular}{lll}
\hline Characteristics & AM & TM \\
\hline Milking facility design & Single Box & Double-three open-tandem \\
Vacuum level, $\mathrm{kPa}$ & 42.0 & 44.0 \\
Pulsation rate, cycles/min & 60 & 60 \\
Pulsation ratio & $65 / 35$ & $64 / 36$ \\
Daily concentrate allowance, $\mathrm{kg}$ & 5 & $2 \times 1$ \\
Concentrate portion/interval, g/s & $50 / 9$ & $100 / 21$ \\
Udder cleaning & Damp cleaning brush & Dry towel \\
\hline
\end{tabular}


came into the barn at $0715 \mathrm{~h}$ were temporarily and loosely tethered in one of the cubicles near the AMS, awaiting the experimenter's preparation for starting the measurements. At that time, they were loosened and allowed to enter the AMS of their own accord.

On the evening before the day of testing, a fecal sample was collected from the rectums from two animals in each group. Then a cannula (Intraflon 2; Vygon, Ecouen, France) was fitted into the jugular vein to allow frequent blood sampling. After insertion, the cannula was filled with sterilized citrate $(32 \mathrm{~g}$, dissolved in 1 $\mathrm{L}$ of saline) to prevent blood clotting. AM-cows were equipped with the heart rate belt. Meanwhile, the AMS site was prepared for measuring quarter milk flow patterns, recording behavior, and collecting blood samples. On test days, human interference was minimized, and the same team of four experimenters was involved all the time, with each individual performing his/her specific task. The first measurements were taken as soon as one of the experimental cows entered the predefined waiting area (Figure 1).

\section{Measurements}

Behavior. A video camera was fitted beside the AMS so that both the cow in the AMS and the robotic arm with the cleaning brush and teat cups could be observed. Similarly, a video camera was used in the tandem parlor for observing the number of steps and kicks as well as the position of the head of a cow during milking, that is, whether her nose was outside or inside the feeding trough. A step is defined as a cow lifting one of her rear legs. A kick was recorded if a cow forcefully and rapidly moved one of her rear legs towards either the milker or the milking cluster. All experimental cows were videotaped during milking, and the behavior and times that marked specific phases in the milking process were analyzed afterwards using the Observer software system (Noldus Information Technology, Wageningen, The Netherlands).

Heart rate. Experimental animals were fitted with a heart rate (HR) monitoring system (Polar Electro Oy, Helsinki, Finland) that recorded mean HR during 5-s intervals (Hopster and Blokhuis, 1994). AM-cows were fitted with the system after the first blood sample was taken in the morning. TM-cows were equipped with the monitoring system in the afternoon before milking. Recordings on AM cows were started either immediately after installation (i.e., if the interval from the previous visit was $>4 \mathrm{~h}$ ) or when the cow showed her first intention to visit the AMS. On average, HR recordings started $111 \mathrm{~min}(\mathrm{AM}, \mathrm{SD}=94)$ and $60 \mathrm{~min}$ $(\mathrm{TM}, \mathrm{SD}=20$ ) before cows were actually milked. HR measurement was stopped after the collection of resid- ual milk. HR data were transferred to a personal computer afterwards for further analysis.

Blood sampling. For determination of baseline values, one blood sample was collected in the morning between $0730 \mathrm{~h}$ and $0830 \mathrm{~h}$ from each cow that was to be tested that day. These samples are referred to as "baseline" samples. During milking, the first blood sample was taken as soon as cows had entered the milking site and before the teats were touched by either the cleaning brush (AM-cows) or the milker (TM-cows). After the first teat was touched for the first time, blood sampling was continued with 1-min intervals throughout milking. Blood was collected into $10-\mathrm{ml}$ evacuated tubes (Vacuette; Greiner B.V., Alphen a/d Rijn, The Netherlands) containing EDTA and stored on ice. Within $1 \mathrm{~h}$ after blood was collected, samples were centrifuged ( $10 \mathrm{~min}, 2500 \times \mathrm{g}, 4^{\circ} \mathrm{C}$ ) and plasma was divided over three different aliquots that were stored at either $-20^{\circ} \mathrm{C}$ (cortisol, oxytocin) or $-80^{\circ} \mathrm{C}$ (catecholamines).

Cortisol. Cortisol (CS) was measured using a timeresolved fluoro-immunoassay in unextracted bovine EDTA-plasma (Erkens et al., 1998). The intra-assay coefficients of variation for control samples with concentrations of $71.1,39.2$, and $10.3 \mathrm{ng} / \mathrm{ml}$ were $8.2,7.9$, and $11.3 \%$, $(n=16)$. The corresponding inter-assay coefficient of variation (CV) were 5.3, 7.4, respectively, and $11.9 \%$ ( $\mathrm{n}=13$ ). The lower detection limit for a $20-\mu \mathrm{l}$ sample was $0.5 \mathrm{ng} / \mathrm{ml}$. Concentrations below this limit were fixed at $0.5 \mathrm{ng} / \mathrm{ml}$.

Catecholamines. For the analysis of adrenaline (A) and noradrenaline (NA), $1 \mathrm{ml}$ was taken from the plasma samples and extracted using a selective liquid extraction, as described by Van der Hoorn et al. (1989). Minor modifications were applied due to the use of electrochemical detection instead of fluorescence detection: 1) dihydroxybenzylamine (DHBA) was used as an internal standard; 2) the washing step with the buffer containing no diphenylborate-ethanolamine complex was omitted. All solvents, except DHBA, and the plasma sample were pipetted into the assay tube. Finally, the appropriate volume of the DHBA solution was added just before a vortex mixer vigorously shook the tube. This resulted in the migration (formation) of the tetraoctyl ammonium bromide-diphenylborate-ethanolamine complexes with the catecholamines into the organic layer of the extraction, whereas the semicarbamazide-sensitive amine oxidase remained in the aqueous layer with no access to DHBA. In this way, the loss of DHBA could be minimized. The resulting extract was injected into an ion-pair reversed-phase HPLC-system with electrochemical detection. The detection limit was $10 \mathrm{pg} / \mathrm{ml}$ for NA and $15 \mathrm{pg} / \mathrm{ml}$ for A. All samples were analyzed in a single assay. The intra- 
assay CV was $1.6 \%$ for NA and $3.2 \%$ for A $(n=20)$. The inter-assay CV was $8.1 \%$ for NA and $16.1 \%$ for $\mathrm{A}(\mathrm{n}=9)$.

Oxytocin. Plasma was analyzed for oxytocin (OT) concentrations using radioimmunoassay, according to Schams (1983). The extraction recovery was $71.3 \pm 8.1 \%$ (mean $\pm \mathrm{SD}$ ) and the CV was $11.4 \%(\mathrm{n}=27)$. The intraassay coefficients of variation of two control samples were $7.9 \pm 2.8$ and $7.8 \pm 2.4 \%(\mathrm{n}=17)$. The inter-assay coefficient of variation was $10.8 \pm 17.3 \%(\mathrm{n}=25)$. The lower limit of assay sensitivity was $0.25 \mathrm{pg} / \mathrm{ml}$ plasma.

Fecal CS metabolites. Fecal samples were stored at $-20^{\circ} \mathrm{C}$ until analysis. Fecal concentrations of the glucocorticoid metabolite 11,17-dioxoandrostanes (DOA) were determined according to the method described by Palme and Möstl (1997).

Quarter milk flow pattern. During milking, milk flow from each quarter was recorded with a specially rebuilt set of Lactocorders (Werkzeug- und Maschinenbau Berneck AG, Balgach, Switzerland) in the AMS as well as in the tandem parlor. Over-milking has been defined as milking that has been continued after milk flow has suddenly dropped below $0.2 \mathrm{~kg} / \mathrm{min}$.

Residual milk. Immediately following milking, cows were stimulated by food to tether themselves in the self-locking feed gate, enabling the experimenter to collect residual milk. To intensively stimulate the OT receptors, a supraphysiological amount (10 IU) of exogenous OT (Apharmo BV, Duiven, The Netherlands) was administered through the jugular cannula. Cows were then re-milked with a portable bucket milker until milk flow ceased. The milk in the bucket was weighed on a digital weighing scale and considered residual milk.

Miscellaneous. Milk production was recorded automatically by either the AMS or the electronic milk meters at every milking and stored in the management system's database. Milk composition and SCC were determined in milk samples that were collected at each milking throughout a 24 -h period. Samples were collected once a week from calving until testing and were preserved with sodium azide/bronopole and refrigerated until analysis (mid-infrared, MilkoScan; FossElectric, Hillerød, Denmark) by a commercial milk analysis laboratory (Dutch Milk Control Station, Zutphen, The Netherlands). For calculating 24 -h values, sample values were corrected for milk volume per milking. BW of all cows were recorded by weighing them on a scale in the week after they were tested.

\section{Statistics}

Milk production per $24 \mathrm{~h}$ was calculated from the milk production per minute for each time cows were milked in the AMS in the week prior to testing. For the TM-cows, 24-h productions were calculated from the 14 a.m. and p.m. milkings in the week before testing. A generalized linear model was used for estimating treatment effects (AM, TM), effects of batch of testing (Batch), and interaction based on normal distribution. For analyzing behavioral data, percentages of time (head upright), or counts (steps), binomial and Poisson distributions, as well as logit and log transformations were applied, respectively. The dispersion of the Poisson distribution was estimated from the Pearson chisquared statistic. Associations between different parameters were derived from Spearman Rank correlations. Statistical significance was considered at $P \leq 0.05$ (F-test). Values are expressed as means \pm standard error of the means. All calculations were performed with the statistical programming language Genstat 5 (1993).

\section{RESULTS}

Based on initial selection criteria, it appeared that both groups were comparable. Means and standard deviations for days in lactation (AM: $37.7 \pm 2.1$; TM: 38.3 \pm 1.9 ), estimated breeding value (AM: $308 \pm 10.7$; TM: $305 \pm 16.2$ ), and BW (AM: $515 \pm 8.2 \mathrm{~kg}$; TM: $517 \pm 9.0$ $\mathrm{kg}$ ) did not differ between groups. Some cows in each group refused to enter the milking site without stimulation by the experimenters. Five AM-cows and 10 TMcows slightly needed to be urged to enter the milking site. In all cases interventions were kept to a minimum.

\section{Performance and Milk Production}

No differences were found in the total time that cows spent in the milking stall between the two milking systems (Table 2). Automatic attachment of the teat cups took significantly more time than attaching the milking cluster by hand. Obviously, more time elapsed in the AM- than in the TM-system between removal of the first and the last teat cup. From the start of udder cleaning until the removal of the last automatic teat cup (independent of waiting times), automatic milking withtook $537 \mathrm{~s}$ compared with $468 \mathrm{~s}$ in the conventional system. Milk production characteristics are summarized in Table 3. No differences were found between AM- and TM-cows in any of the recorded parameters except for the number of milkings per day $(P<0.05)$.

\section{Behavior and Heart Rate}

None of the cows kicked during udder preparation or during milking. Steps primarily occurred when the teats were cleaned or when the teat cups were either attached or removed. AM-cows (0.5) stepped fewer times $(P<0.05)$ during udder cleaning and teat cup attachment than TM-cows (2.6), whereas AM-cows (2.1) 
Table 2. Duration(s) of the various phases in the milking process during automatic (AM [Lely Astronaut, model 20; $\mathrm{n}=18]$ ) and conventional, tandem-parlor (TM $[\mathrm{n}=18]$ ) milking of primiparious cows.

\begin{tabular}{lccrrr}
\hline & \multicolumn{2}{c}{ AM } & & TM \\
\cline { 2 - 3 } \cline { 5 - 6 } Phases in the milking process & Mean & SEM & & Mean & SEM \\
\hline Idle time after entrance & 17 & 1.4 & 60 & 8.9 \\
Cleaning teats & 45 & 2.9 & 31 & 2.9 \\
Teat cup attachment & 66 & 17.3 & 51.1 & 5 & 0.2 \\
Milking 4 teats simultaneously & 250 & 22.0 & & $<1$ & 0.2 \\
Removal of teat cups & 176 & 0.4 & 51 & 8.0 \\
Idle time before exit & 12 & 34.0 & 575 & 27.6 \\
Total time & 566 & &
\end{tabular}

stepped more frequently $(P<0.05)$ than TM-cows $(0.3)$ during teat cup removal. The total number of steps during milking did not differ $((P<0.05)$ between AM(4.7) and TM-cows (8.0).

During their stay in the milking stall, AM-cows spent less time (39\%) than TM-cows (67\%) standing with their heads outside the feeding trough $(P<0.05)$. From their arrival at the milking site until the attachment of the last teat cup, AM-cows spent $68 \%$ of their time standing with their noses in the feeding trough, in contrast $(P<$ 0.01 ) with TM-cows, which held their noses inside the feeding trough $29 \%$ of the time.

Figure 2 illustrates that the mean HR in AM-cows in the various phases during the course of milking was consistently lower than in TM-cows $(P<0.05)$. It also indicates that the difference in HR was not restricted to the actual milking, but already existed while the cows were in the collection yard (TM-cows) or in the cubicle barn (AM-cows) in the half hour before milking. During this period, mean HR in TM-cows, averaged over 5-min periods, ranged between 90 and $91 \mathrm{bpm}$, whereas HR in AM-cows was between 78 and $80 \mathrm{bpm}$. It should be noted that in this period all TM-cows were waiting in the collection yard, whereas most of the AMcows spent their time in the cubicle barn in the predefined waiting area. After cows had entered the milking stall, HR increased $10 \mathrm{bpm}$ in both groups and gradu- ally returned to premilking levels. Treatment effects Group and Batch accounted for 22 to $43 \%$ of the variance in HR during the 30 min before milking but only for 15 to $22 \%$ during all different stages in the milking process. Averaged over the period during which the first five blood samples were taken, mean HR in TM-cows was significantly $(P<0.05)$ higher than in AM-cows.

Adrenaline. Unexpected peaks in the chromatograms of 2 TM-cows and of 1 AM- and 5 TM-cows prohibited an unbiased interpretation of A and NA concentrations, respectively, and the values were considered missing values. Figure 3 illustrates that A concentrations in plasma were significantly $(P<0.05)$ lower in AM-cows than in TM-cows during the first 4 min after cows had arrived at the milking site. The highest values were found in TM-cows immediately after they had entered the stall. During milking, A concentrations returned to pretest values within $5 \mathrm{~min}$. On average (bars), AM-cows tended $(P=0.057)$ to have lower A concentrations than TM-cows. Also the maximum A concentrations in AM-cows $(55.4 \mathrm{pg} / \mathrm{ml})(P=0.01)$ were about half those in TM-cows $(93.1 \mathrm{pg} / \mathrm{ml})$. Baseline values from samples collected in the cows' home environment in the morning were low and did not differ $(P>$ 0.05 ) between groups. For successive samples, factors in the model (Group, Batch) accounted for 0 to $23 \%$ of the total variance in A concentrations.

Table 3. Milk production characteristics of primiparous cows milked in an automatic (Lely Astronaut, model $20=\mathrm{AM}, \mathrm{n}=18$ ) or in a conventional (tandem parlor $=\mathrm{TM}, \mathrm{n}=18$ ) milking system.

\begin{tabular}{|c|c|c|c|c|}
\hline \multirow[b]{2}{*}{ Milk production characteristics } & \multicolumn{2}{|c|}{$\mathrm{AM}$} & \multicolumn{2}{|c|}{$\mathrm{TM}$} \\
\hline & Mean & SEM & Mean & SEM \\
\hline No. daily milkings ( $1 \mathrm{wk}$ before test) & $3.0^{\mathrm{a}}$ & 0.19 & $2.0^{\mathrm{b}}$ & \\
\hline 24-h milk yield, kg ( 1 wk before test) & 33.4 & 1.95 & 34.3 & 0.93 \\
\hline Fat, \% (1 wk before test) & 4.0 & 0.16 & 4.3 & 0.12 \\
\hline Protein, \% (1 wk before test) & 3.2 & 0.06 & 3.3 & 0.05 \\
\hline Lactose, \% (1 wk before test) & 4.7 & 0.04 & 4.8 & 0.03 \\
\hline Somatic cells, $\times 1000$ ( $1 \mathrm{wk}$ before test $)$ & 53.1 & 20.74 & 51.9 & 13.95 \\
\hline Milk yield during test, kg & 13.8 & 0.88 & 15.5 & 0.50 \\
\hline Residual milk, kg & 1.8 & 0.39 & 1.5 & 0.24 \\
\hline Residual milk, \% total volume & 10.2 & 1.65 & 8.6 & 1.35 \\
\hline
\end{tabular}

${ }^{\mathrm{a}, \mathrm{b}}$ Different superscripts indicate significant $(P<0.05)$ difference between milking systems. 


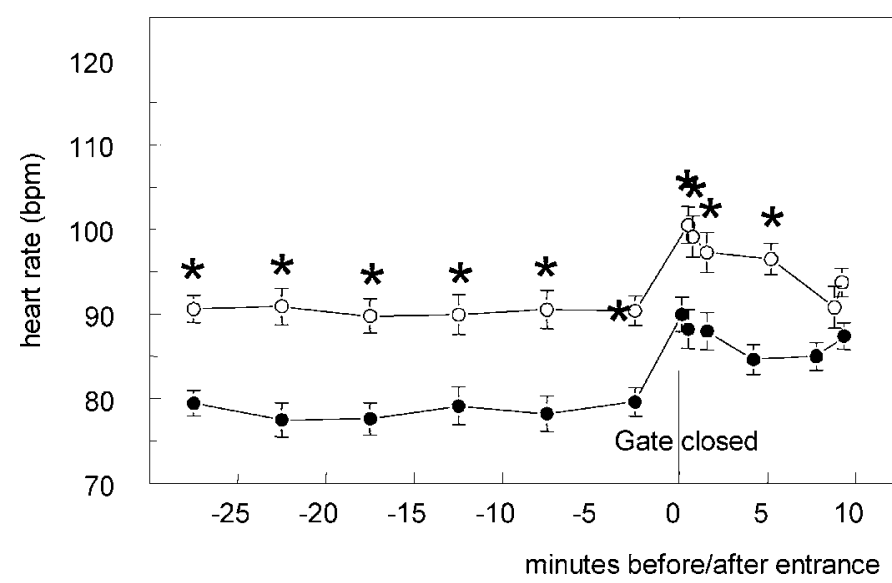

Figure 2. Mean heart rate of primiparous cows milked in either an automatic (AM, closed circle) or a conventional, tandem-parlor (TM, $\mathrm{n}=18$; open circle) milking system. Error bars represent standard errors; asterisks indicate differences $(P<0.05)$ between AMand TM-cows.

Noradrenaline. A similar pattern was found in NA concentrations, albeit more variable between animals within groups and, therefore, less significant (Figure 3 ). Averaged over the first 8 min of the milking process (bars), differences between groups were not significant $(P=0.15)$. Also for NA, AM-cows showed lower concentrations than TM-cows, especially at the start of milking. Also the baseline values tended $(P=0.075)$ to be lower in AM-cows. Furthermore, baseline values and values during milking were comparable in AM-cows, in contrast to the increased values in TM-cows. As was the case with A concentrations, increased NA concentrations returned to baseline within $5 \mathrm{~min}$. Maximum NA concentrations were lower $(P=0.04)$ in AM-cows $(447.5 \mathrm{pg} / \mathrm{ml})$ than in TM-cows $(637.7 \mathrm{pg} / \mathrm{ml})$. For successive samples, factors in the model (Group, Batch) accounted for 6 to $30 \%$ of the total variance in NA concentrations. NA-to-A ratios were significantly higher $(P=0.05)$ in AM-cows (14.4) than in TM-cows (6.4) in the first blood sample only.

Oxytocin. As expected, baseline OT concentrations were low and varied between 1.0 and $9.7 \mathrm{pg} / \mathrm{ml}$ (Figure 3 ). After tactile stimulation of the teats (second blood sample) by either the cleaning brush (45 s [Table 2]) or the milker (31 s [Table 2]), OT had increased up to mean concentrations of $53.1 \mathrm{pg} / \mathrm{ml}$ in AM-cows and 93.6 $\mathrm{pg} / \mathrm{ml}$ in TM-cows $(P=0.23)$. Although not significant, the release of OT in AM-cows seems to be lower at the start of milking, but a high concentration was significantly prolonged $(P<0.05)$ at the end of the milking process. For the various sample numbers, factors in the model (Group, Batch) accounted for 1 to $19 \%$ of the total variance in $\mathrm{OT}$ concentrations.
Cortisol and fecal cortisol metabolites. Figure 3 shows that plasma CS concentrations at the start of milking in AM-cows, as well as in TM-cows, did not differ from baseline concentrations. CS levels gradually increased during milking. CS concentrations significantly increased $(P=0.02)$ with milking time in both groups, reaching maximum concentrations in individual animals of $27.2 \mathrm{ng} / \mathrm{ml}$ in AM-cows and $21.0 \mathrm{ng} / \mathrm{ml}$ in TM-cows. Although CS concentrations seem to be consistently higher in AM-cows than in TM-cows, these differences were not significant and only tended $(P=$ 0.097 ) to be different in the second blood sample. Averaged over the first five blood samples (bars), AM-cows tended $(P=0.075)$ to have higher plasma CS concentrations compared with TM-cows. Mean CS concentrations in morning samples were equal between groups $(P=$ $0.23)$. No difference was found between AM-cows and TM-cows in fecal DOA concentrations. Median values for DOA were $115 \mathrm{nmol} / \mathrm{kg}$ for AM-cows (range: 25.2 to 294.8) and $167 \mathrm{nmol} / \mathrm{kg}$ for TM-cows (range: 44.4 to 278.8). Baseline CS concentrations correlated positively $\left(\mathrm{R}_{\mathrm{sp}}=0.54 ; P=0.002\right)$ with fecal DOA concentrations.

Quarter milk flow patterns. Due to technical problems with the equipment, the milk flow of one of the four quarters was not recorded in three TM-cows. In the analysis, these data were regarded as missing data. Only one TM-cow showed a clear bimodal milk flow pattern in all four quarters. Milk flow patterns clearly showed that the AMS occasionally had difficulties attaching the teat cups, although it was finally successful in all cows. In one cow, teat cups were only attached to both front teats when the rear quarters were almost emptied. In another AM-cow, the teat cups were alternately attached to and detached from the front quarters, probably because no milk flow was detected in one of those teats.

From the detailed information of the quarter milk flow curves, parameters like milk flow, time to collect percentiles of the total milk yield and over-milking time were calculated. Maximum quarter milk flow (AM: 885, 806, 881, $766 \mathrm{~g} / \mathrm{min}$, and TM: 868, 808, 952, $937 \mathrm{~g} /$ min for LR, RR, RF, LF quarters, respectively) was comparable for both groups. Although the four quarters of a cow are milked more synchronously in the tandem parlor, the maximum udder milk flow did not differ $(P$ $>0.05)$ between AM- $(2.82 \mathrm{~kg} / \mathrm{min})$ and TM-cows $(3.38$ $\mathrm{kg} / \mathrm{min}$ ). As could be expected, AM-cows had shorter ( $P$ $<0.001$ ) over-milking times (AM: 4.4, 10.7, 4.4, $4.2 \mathrm{~s}$, and TM: 72.6, 85.6, 119.8, $132.9 \mathrm{~s}$ for LR, RR, RF, LF, respectively) than TM-cows.

\section{DISCUSSION}

\section{Physiological and Behavioral Responses During Milking}

A concentrations during milking (AM: $34.2 \mathrm{pg} / \mathrm{ml}$; TM: $49.4 \mathrm{pg} / \mathrm{ml}$ ) were comparable with concentrations 

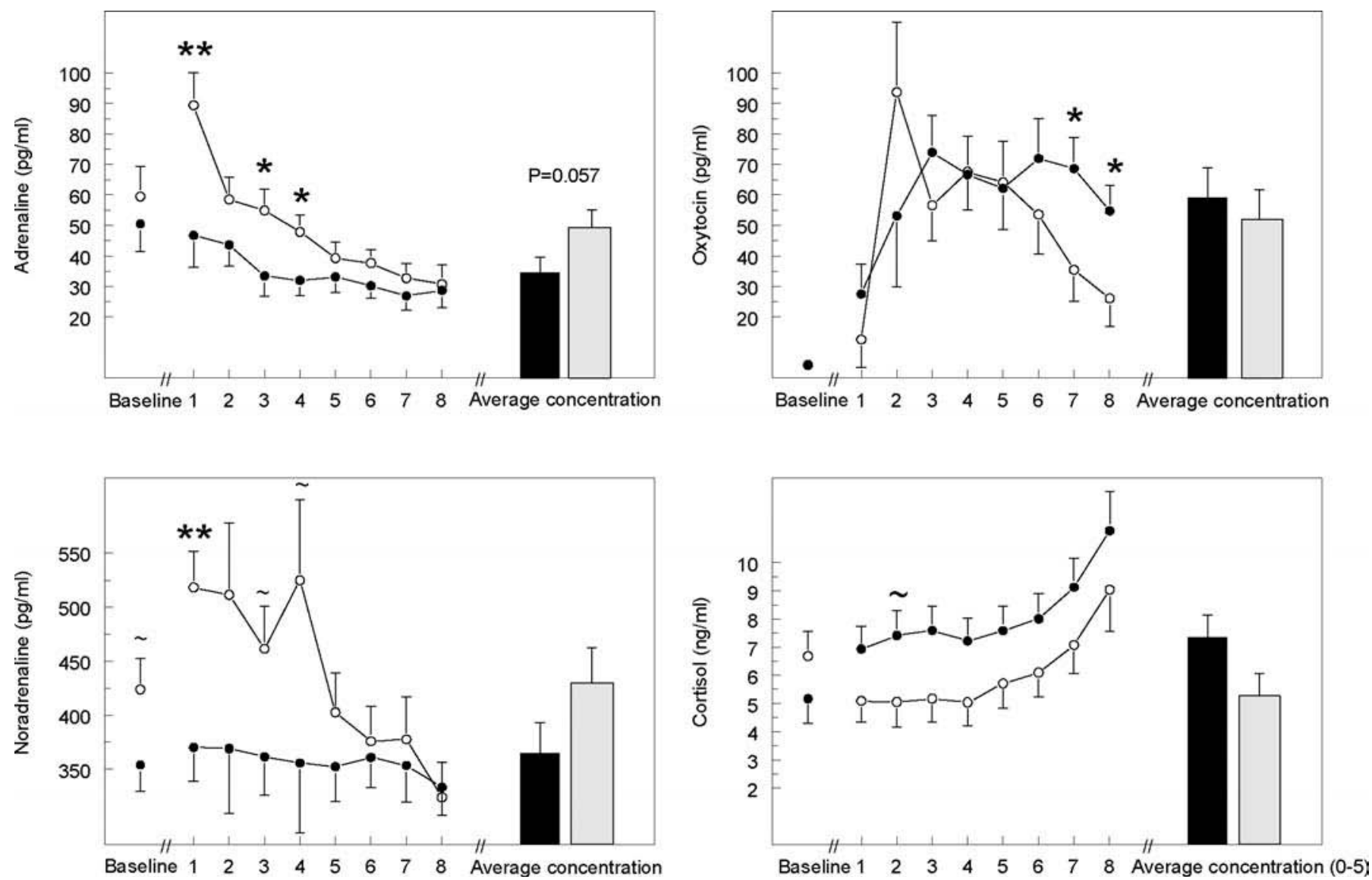

Figure 3. Mean plasma adrenaline, noradrenaline, oxytocin, and cortisol concentrations in primiparous cows milked in either an automatic (AM, $\mathrm{n}=18$; closed circle) or a conventional, tandem-parlor, (TM, $\mathrm{n}=18$; open circle) milking system. Bars on the right illustrate average concentrations for AM (black) and TM (gray) cows. Error bars represent standard errors; asterisks indicate differences $(* P<0.05$; $* * P<$ $0.01)$ between AM- and TM-cows. A tendency $(0.05<=\mathrm{P}<0.10)$ is indicated by the " " sign.

measured in control cows during milking (Blum et al., $1989 ; 60 \pm 8 \mathrm{pg} / \mathrm{ml})$ and with those in cows kept under thermoneutral $\left(20^{\circ} \mathrm{C}, 50 \% \mathrm{rh}\right)$ conditions (Katti et al., $1987 ; 52.5 \mathrm{pg} / \mathrm{ml})$. The maximum A level was about half as high as that reported by Kondo and Hurnik (1988; $158 \pm 75 \mathrm{pg} / \mathrm{ml})$ and Rausch et al. (1989; $179 \pm 74 \mathrm{pg} /$ $\mathrm{ml}$ ) in undisturbed cows. These data and much higher A concentrations, that is, between 400 and $500 \mathrm{pg} / \mathrm{ml}$, in cows that were subjected to different branding procedures (Lay et al., 1992) support our view that cows in the present experiment expressed functional neuroendocrine responses during milking without experiencing stress.

Further evidence for this view was derived from NA concentrations. In plasma collected from control animals in familiar environments, concentrations of 119.0 $\mathrm{pg} / \mathrm{ml}$ (Katti et al., 1987), $211 \pm 13 \mathrm{pg} / \mathrm{ml}$ (Blum et al., 1989), and $179 \pm 74 \mathrm{pg} / \mathrm{ml}$ (Rausch et al., 1989) were previously reported and can be considered baseline values. Compared with these baseline values, average con- centrations in AM-cows $(364.1 \mathrm{pg} / \mathrm{ml})$ and TM-cows $(429,7 \mathrm{pg} / \mathrm{ml})$ appeared to be higher but markedly lower than concentrations of $3.53 \pm 1.23 \mathrm{ng} / \mathrm{ml}$ in control cows in familiar tie stalls (Kondo and Hurnik, 1988). The relatively low NA concentrations found in the current study, therefore, further support the idea that cows were not stressed during milking in either system.

Mean plasma CS concentrations were between 5 and $8 \mathrm{ng} / \mathrm{ml}$ during the first $5 \mathrm{~min}$ of milking. Hopster et al. (1999), using the same assay, concluded that $69.4 \%$ of 307 baseline CS samples had concentrations below $3 \mathrm{ng} / \mathrm{ml}$, whereas $13.7 \%$ of the samples contained $6 \mathrm{ng} /$ $\mathrm{ml}$ CS or more. Similar CS concentrations have also been defined by others as being baseline values (Lefcourt et al., 1993; Nakao et al., 1993; Bruckmaier et al., 1996). Mean CS values during the first 5-min of milking in both AM- and TM-cows can, therefore, safely be considered to be in the normal range of baseline concentrations. Since the stress-induced release of CS from the adrenal cortex into the peripheral blood of 
cows is delayed for about 5 to $10 \mathrm{~min}$ after the first exposure to a stressor, these values particularly reflect what the cow experienced while waiting in front of the AMS, rather than during milking.

Bimodal quarter milk flow patterns, indicating delayed ejection of alveolar milk into the cisternal cavities and consequently suboptimal milk removal, was found in one TM-cow only. Clearly, manual (TM-cows) and mechanical (AM- and TM-cows) stimulation of the teats effectively stimulated the release of OT from the posterior pituitary gland in cows in both groups. Baseline OT concentrations were comparable to those reported by Mayer et al. (1991), Bruckmaier and Blum (1996), and Tančin et al. (2000b) and ranged between 2 and 10 $\mathrm{pg} / \mathrm{ml}$. Immediately after stimulation of the teats, OT concentrations rose markedly and remained elevated during the course of milking (Figure 3). Both milking systems thus created essential conditions for continuous milk ejection during the whole milking procedure (Bruckmaier and Blum, 1998). Compared with milkingrelated OT concentrations after stimulation (Mayer et al., 1991) in cows 8 wks postpartum (18.3 \pm 15.9$)$, by Bruckmaier and Blum (1996) 1 to 2 min after start of stimulation ( $43.9 \pm 12.8)$, or by Tančin et al. (2000b) in nonpregnant cows $(16.7 \pm 0.4 \mathrm{pg} / \mathrm{ml})$, OT concentrations in both AM- and TM-cows were obviously higher. Because these authors mainly used multiparous Brown Swiss and Simmental cows, differences between parities or breeds may have attributed to the differences found in OT concentrations.

In addition to the high and prolonged OT concentrations in our study, peak milk flow rates further support the notion that milk ejection was effectively realized and not hampered by stress during milking. Average peak milk flow rate (AM-cows: 2.8, TM-cows: $3.4 \mathrm{~kg} /$ min) was in line with peak flow rates of $2.3,2.7$, and $3.9 \mathrm{~kg} / \mathrm{min}$ found by Bruckmaier and Blum (1996), Tančin et al. (2000b), and Bruckmaier et al. (1996), respectively, in control cows. Furthermore, the amount of residual milk in both AM- and TM-cows of $10.2 \%$ and $8.6 \%$, respectively, was comparable to the $8 \%$ and $14 \%$ which was found in multiparous cows (Bruckmaier et al., 1993, 1996). The release of OT, the peak milk flow rates during milking, as well as the amounts of residual milk, all argue in favor of an undisturbed milk ejection reflex in both AM- and TM-cows. The daily milk yield in AM-cows was lower than in TM-cows, albeit not significantly lower. Because no indications were found so far that AM-cows were stressed, it is unlikely that the absence of an expected increase in daily milk yield in AM-cows resulted from stress during milking. We speculate, therefore, that forced cow traffic could have restricted the low-ranking animals' access to the AMS and thus to the feeding gate, resulting in a reduced energy intake and milk production. Another explanation, however, can be that effects of frequent milking on milk production are most prominent during late lactation in multiparous cows.

Further evidence was provided by the HR patterns and behavioral reactions during milking that cows did not experience stress in either system. Roughly, HR increased with $10 \%$ soon after cows had entered the milking stall and returned to premilking values at the end of milking. Royle et al. (1992) compared mean HR during the first 6 min of milking in mid-lactation Holstein cows with mean HR during the 6 -min period before milking and reported a relative increase of $20 \%$. In the same study, no differences were found in tachycardiac response to milking when cows were milked twice or five times a day. As compared with premilking HR, Hopster et al. (1998) previously determined an increase of $17 \%$ during the first minute of milking. The average HR during the premilking period in this study was within the normal variation in baseline HR $(83.2$ \pm 12.6 ), as reported in dairy cows by Kondo and Hurnik (1988). These normal HR responses are in accordance with the behavior of the animals. The number of steps during milking (AM-cows: 4.7; TM-cows: 8.0 ) was comparable to the number $(5.5 \pm 2.3)$ found in a previous study (Hopster et al., 1998). Moreover, none of the cows kicked during milking.

\section{Human-Animal Interaction}

In mammals, NA is the predominant circulating catecholamine that is released during moderate exercise as a result of neuronal spillover, rather than from adrenal secretion (De Boer et al., 1990; Korte et al., 1992). A, as has been clearly demonstrated in rats (Scheurink et al., 1996), is specifically released during psychological stress. In this study, differences in A and NA concentrations between AM- and TM-cows were predominantly found immediately after cows had entered the milking stall. This and the gradual decline of A and NA concentrations during milking support the idea that factors associated with the arrival at the milking site itself, rather than factors connected to the milking process, activated the sympathetic nervous system in TM- cows. This corresponds with the experimenters' impression that AM-cows behaved in a less-agitated manner when fetched in the barn for habituation and during application of the girth belt. We speculate that this may be because AM-cows, in contrast with TM-cows, are not rushed by the milker into the collection yard two times each day. They are expected to visit the AMS of their own accord, and individual cows are only occasionally urged by the herdsman to do so. This would probably limit negative learning experiences. As long as contacts 
with humans are neutral or positive and are not limited to situations that involve some kind of unpleasant treatment, cows (e.g., AM-cows) are likely to experience less stress when handled by humans. In dairy cows, a learned aversion to a particular person as a result of repeated rough handling may even become apparent in locations other than where the handling occurred (Rushen et al., 1999). For TM-cows, the milking parlor was possibly one of these locations; thus, the animals became frightened when they entered the milking stall.

\section{CONCLUSIONS}

The results indicate that in the present study cows were not stressed during milking in either of the two milking systems. Automatic milking, in the way it is executed by the Lely Astronaut, resulted in only marginal differences in functional behavioral and physiological stress responses during milking in favor of the AMS. We therefore conclude that, as far as the welfare of the dairy cow during milking is concerned, automatic milking and conventional milking are equally acceptable.

\section{ACKNOWLEDGMENTS}

We thank the staff of the experimental facilities of ID-Lelystad at the Runderweg for their support throughout the study, in particular, Kees Steenbergen, Jaap Smit, and Dick Luiten. We also thank Erich Möstl for determining fecal cortisol metabolites and Bas Engel for statistical advice. We are grateful to Janet Ball, Hamilton, New Zealand who assisted with the English in the paper and to two anonymous reviewers for their valuable comments on the manuscript. This study was supported by a grant from Lely Industries NV, The Netherlands.

\section{REFERENCES}

Blum, J. W., D. Schams, and R. M. Bruckmaier. 1989. Catecholamines, oxytocin and milk removal in dairy cows. J. Dairy Res. 56:167-177.

Bruckmaier, R. M., D. Schams, and J. W. Blum. 1993. Milk removal in familiar and unfamiliar surroundings: Concentration of oxytocin, prolactin, cortisol and $\beta$-endorphin. J. Dairy Res. 60:449456.

Bruckmaier, R. M., and J. W. Blum. 1996. Simultaneous recording of oxytocin release, milk ejection and milk flow during milking of dairy cows with and without prestimulation. J. Dairy Res. 63:201-208.

Bruckmaier, R. M., H.-U. Pfeilsticker, and J. W. Blum. 1996. Milk yield, oxytocin and $\beta$-endorphin gradually normalize during repeated milking in unfamiliar surroundings. J. Dairy Res. 63:191-200.

Bruckmaier, R. M., and Blum, J. W. 1998. Oxytocin release and milk removal in ruminants. J. Dairy Res. 81:939-949.

De Boer, S. F., J. L. Slangen, and J. Van der Gugten. 1990. Plasma catecholamine and corticosterone levels during active and pas- sive shock-prod avoidance behavior in rats: Effects of chlordiazepoxide. Physiol. Behav. 47:1089-1098.

Erkens, J. H. F., S. J. Dieleman, R.A. Dressendörfer, and C. J. Strasburger. 1998. A time-resolved fluoroimmunoassay for cortisol in unextracted bovine plasma or serum with optimized procedures to eliminate steroid binding protein interference and to optimize non-specific streptavidin-europium binding. J. Steroid Biochem. Mol. Biol. 67(2):153-161.

Genstat 5 Committee 1993. Genstat 5, Release 3 Reference Manual. United Kingdom, Oxford, Clarendon Press, United Kingdom.

Hogeveen, H., J. D. Miltenburg, S. den Hollander, and K. Frankena. 2000. A longitudinal study on the influence of milking three times a day on udder health and milk production. Pages 297298 in Robotic Milking, Proc. Int. Symp. H. Hogeveen and A. Meijering, eds. August 17-19, 2000. Lelystad, The Netherlands.

Hopster, H., and H. J. Blokhuis. 1994. Validation of a heart rate monitor for measuring a stress response in dairy cows. Can. J. Anim. Sci. 74:465-474.

Hopster, H., J. T. N. Van der Werf, and H. J. Blokhuis. 1998. Side preference of dairy cows in the milking parlour and its effects on behaviour and heart rate during milking. Appl. Anim. Behav. Sci. 55:213-229.

Hopster, H., J. T. N. Van der Werf, J. H. F. Erkens, and H. J. Blokhuis. 1999. Effects of repeated jugular puncture on plasma cortisol concentrations in loose-housed dairy cows. J. Anim. Sci. 77:708-714.

Katti, P. S., H. D. Johnson, and R. R. Gaddis. 1987. Stress effects of environmental heat on plasma and milk catecholamines in dairy cattle. J. Dairy Sci. 70 (Suppl. 1):123.

Ketelaar-de Lauwere, C. C., S. Devir, and J. H. M. Metz. 1996. The influence of social hierarchy on the time budget of cows and their visits to an automatic milking system. Appl. Anim. Behav. Sci. 49:199-211.

Kondo, S., and J. F. Hurnik. 1988. Behavioral and physiological responses to spatial novelty in dairy cows. Can. J. Anim. Sci. 68:339-343.

Korte, S. M., G. A. Bouws, J. M. Koolhaas, and B. Bohus. 1992. Neuroendocrine and behavioral responses during conditioned active and passive behavior in the defensive burying/probe avoidance paradigm: Effects of ipsapirone. Physiol. Behav. $52: 355-361$.

Lay, D. C., Jr., T. H. Friend, R. D. Randel, C. L. Bowers, K. K. Grissom, and O. C. Jenkins. 1992. Behavioral and physiological effects of freeze or hot-iron branding on crossbred cattle. J. Anim. Sci. 70:330-336.

Lefcourt, A. M., J. Bitman, S. Kahl, and D. L. Wood. 1993. Circadian and ultradian rhythms of peripheral cortisol concentrations in lactating dairy cows. J. Dairy Sci. 76:2607-2612.

Mayer, H., R. M. Bruckmaier, and D. Schams. 1991. Lactational changes in oxytocin release, intramammary pressure and milking characteristics in dairy cows. J. Dairy Res. 58:159-169.

Nakao, T., T. Sato, M. Moriyoshi, and K. Kawata. 1994. Plasma cortisol response in dairy cows to vaginoscopy, genital palpation per rectum and artificial insemination. J. Vet. Med. A41:16-21.

NRS. 1996. Chapter E-9: Netto-melkgeldindex (INET, Net Milk Revenue Index). Koninklijk Nederlands Rundvee Syndicaat, Arnhem, The Netherlands.

Palme, R., and E. Möstl. 1997. Measurement of cortisol metabolites in faeces of sheep as a parameter of cortisol concentration in blood. Z. Säugetierkunde - Int. J. Mammal Biol. 62 (Suppl. 2): 192-197.

Prescott, N. B., T. T. Mottram, and A. J. F. Webster. 1998. Relative motivations of dairy cows to be milked or fed in a Y-maze and an automatic milking machine. Appl. Anim. Behav. Sci. 57:2333. Rausch, W.-D., A. Hofer, and E. Möstl. 1989. Catecholamine levels during the periparturient period in the cow. Pages 705712 in Stress: Neurochemical and Humoral Mechanisms. G. R. Van Loon, R. Kvetnanský, R. McCarty, and J. Axelrod, ed. Gordon and Breach Science Publishers, New York, NY.

Royle, C., P. C. Garnsworthy, A. J. McArthur, and T. B. Mepham. 1992. Effects of frequent milking on heart rate and other physiological variables in dairy cows. Pages $237-243$ in Prospects for 
Automatic Milking. Proc. Int. Symp. Prospects for Automatic Milking. A. H. Ipema, A. C. Lippus, J. H. M. Metz, and W. Rossing, ed. Pudoc Scientific Publishers, Wageningen, The Netherlands.

Rushen, J., A. M. De Passilé, and L. Munsgaard. 1999. Fear of people by cows and effects on milk yield, behavior and heart rate at milking. J. Dairy Sci. 82:720-727.

Schams, D. 1983. Oxytocin determination by radioimmunoassay. III. Improvement to subpicogram sensitivity and application to blood levels in cyclic cattle. Acta Endocrinol. 103:180-183.

Scheurink, A. J. W., S. F. De Boer, G. Van Dijk, and A. B. Steffens. 1996. Central and peripheral mechanisms involved in the regulation of sympathoadrenal outflow. Pages 227-241 in Stress: Molecular Genetic and Neurobiological Advantages. R. McCarty, G. Aguillera, E. Sabban, and R. Kvetnansky, ed. Gordon and Breach Science Publishers S. A., New York, NY.
Stefanowska, J., M. Plavsic, A. H. Ipema, and M. M. W. B. Hendriks. 2000. The effect of omitted milking on the behaviour of cows in the context of cluster attachment failure during automatic milking. Appl. Anim. Behav. Sci. 67:277-291.

Tančin, V., W. D. Kraetzl, and D. Schams. 2000a. Effects of morphine and naloxone on the release of oxytocin and on milk ejection in dairy cows. J. Dairy Res. 67:13-20.

Tančin, V., D. Schams, and W. D. Kraetzl. 2000b. Cortisol and ACTH release in dairy cows in response to machine milking after pretreatment with morphine and naloxone. J. Dairy Res. 67:467474.

Van der Hoorn, F. A. J., F. Boomsma, A. J. Man in't Veld, and M. A. D. H. Schalekamp. 1989. Determination of catecholamines in human plasma by high-performance liquid chromatography: Comparison between a new method with fluorescence detection and an established method with electrochemical detection. J. Chromatogr. 487:17-28. 